\title{
Sistema de Suplementação Alimentar para Bovinos de Corte em Pastejo. Simulação
}

\author{
Rogério de Paula Lana1
}

\begin{abstract}
RESUMO - Objetivou-se com este trabalho demonstrar a aplicação do Sistema Viçosa de Formulação de Rações na recomendação de suplementos alimentares para bovinos de corte com 200 e $400 \mathrm{~kg}$ de peso corporal, em diferentes épocas de diferimento e utilização dos pastos. Verificou-se que, para animais com $200 \mathrm{~kg}$ de peso corporal ganhar $1 \mathrm{~kg} / \mathrm{dia}$ no pasto diferido em fevereiro e utilizado em junho ou setembro, ou diferido em abril e utilizado em junho ou setembro, houve necessidade de 2,16; 3,60; 0,50 e 3,23 kg de suplemento/ animal/dia, respectivamente. Para animais com $400 \mathrm{~kg}$ de peso corporal, a necessidade de suplementação foi ainda maior: 4,21; 5,86;2,48 e 5,24 kg/animal/dia. O teor de uréia (1,4;0,9;9,8 e 0,9; e 5,3;0,9; 16,5 e 0,4\%, respectivamente) e o teor e a composição da mistura mineral nos suplementos também variaram muito nessas diferentes situações. O Sistema Viçosa de Formulação de Rações possibilitou formular suplementos específicos para cada situação, de uma maneira rápida e eficiente, com base em equações de estimativas de consumo de suplemento em função do peso corporal do animal e nível de uréia, permitindo formular suplementos apenas para corrigir as deficiências nutricionais ou para se obter ganhos de peso mais elevados.
\end{abstract}

Palavras-chave: consumo, desempenho, diferimento, nutrientes, uréia

\section{A System of Feed Supplementation for Beef Cattle under Grazing. Simulation}

\begin{abstract}
This work aimed to demonstrate the application of a computer system (Sistema Viçosa de Formulação de Rações) in the recommendation of feed supplements for beef cattle with 200 and $400 \mathrm{~kg}$ of body weight, on different pasture deferring and utilization periods. In order to an animal of $200 \mathrm{~kg}$ of body weight achieve $1 \mathrm{~kg}$ of daily gain in a pasture deferred in February and used in June or September, or deferred in April and used in June or September, it was necessary 2.16, 3.60, 0.50 and $3.23 \mathrm{~kg}$ of supplement/animal/day, respectively. In order to an animal of $400 \mathrm{~kg}$ of body weight, the need for supplementation was even greater: $4.21,5.86,2.48$ and $5.24 \mathrm{~kg} /$ animal/day. The urea content $(1.4,0.9,9.8$ and $0.9 ;$ and $5.3,0.9,16.5$ and $0.4 \%$, respectively) and the mineral mixture content and composition in the supplements also changed dramatically in these different situations. The computer system allows to formulate specific supplements for each situation, in a rapid and efficient way, based on equations of supplement intake as a function of animal body weight and urea level, allowing to make supplements only for correction of nutritional deficiency or to obtain higher daily gains.
\end{abstract}

Key Words: deferring, intake, nutrients, performance, urea

\section{Introdução}

As gramíneas tropicais apresentam mudança drástica na composição ao longo do ano, em função do avanço do seu estádio vegetativo. A digestibilidade pode variar de $60 \%$ nas águas a $40 \%$ na seca, devido ao aumento no teor de lignina e de fibra na planta (Van Soest, 1994), reduzindo o suprimento de energia para os animais. O teor de proteína varia de 10-12\% no início do crescimento vegetativo a $2-4 \%$ no final do ciclo, após a floração. Além da redução no suprimento de energia e proteína, ocorre diminuição da concentração de minerais e vitaminas, podendo levar à redução no ganho ou perda de peso ou em casos extremos, à morte dos animais (Tosi, 1997).

A qualidade das pastagens varia mais em função do estádio vegetativo do que em função da espécie ou variedade da planta. No Brasil central, existem dois períodos distintos em relação à qualidade das pastagens: período das águas, em que ocorre maior concentração de nutrientes na planta, e período seco, em que há redução do conteúdo de nutrientes e disponibilidade de forragem ( $80 \%$ da disponibilidade total no período das águas e $20 \%$ no período seco). Segundo Poppi \& McLennan (1995), as flutuações estacionais na disponibilidade e qualidade das pastagens resultam na elevada idade ao abate dos animais.

Uma das formas de se complementar o eventual déficit de proteína e energia que as pastagens apresentam durante o ano é por intermédio da suplementação. Esta é feita principalmente com alimentos concentrados ou com volumosos de boa qualidade; no entanto, é importante ajustar os níveis de energia e proteína do suplemento em relação à pastagem (Lesch et al., 1963). 
De modo geral, as principais vantagens da suplementação são: aumentar o fornecimento de nutrientes para os animais, utilizar as pastagens de modo mais adequado, evitar a subnutrição, melhorar a eficiência alimentar, auxiliar na desmama precoce, reduzir a idade do primeiro parto, reduzir o intervalo entre partos, diminuir a idade de abate, aumentar a taxa de lotação das pastagens e auxiliar na terminação de animais de descarte (Muller, 1980; Seiffert, 1982; Cachapuz, 1991; Pascoal \& Restle, 1996; Pascoal et al., 1997; Restle et al., 1997).

O Sistema Viçosa de Formulação de Rações (Lana, 2000) permite formular suplementos para animais em pastagens, para corrigir a deficiência dos nutrientes limitantes ou para permitir ganhos de peso mais elevados que aqueles permitidos pela disponibilidade de nutrientes das pastagens, com uso de maior quantidade de suplementos. Neste caso, deve-se levar em consideração a relação benefício-custo com a suplementação, como por exemplo o menor custo com alimentação por unidade de aumento no ganho de peso, redução da idade ao abate e aumento da fertilidade nas fêmeas.

Objetivou-se com este trabalho demonstrar a aplicação do Sistema Viçosa de Formulação de Rações (Lana, 2000) na recomendação de suplementos alimentares para bovinos de corte em pastejo, com diferentes épocas de diferimento e utilização, visando corrigir as deficiências nutricionais apresentadas pela pastagem ou para obter desempenhos mais elevados.

\section{Material e Métodos}

O trabalho de simulação da suplementação alimentar foi desenvolvido utilizando-se dados de composição de pastos de Brachiaria brizanta cv. Marandu, em função da época de diferimento e utilização (Tabela 1), publicados por Costa et al. (1993). As informações utilizadas foram o teor de proteína bruta e digestibilidade in vitro da matéria seca, assumindo-se que este último representa o teor de nutrientes digestíveis totais.

Com base nestas informações e levando-se em consideração a composição mineral das forrageiras presentes no banco de dados da composição de alimentos do Sistema Viçosa de Formulação de Rações (Lana, 2000; Tabela 2), foram feitas simulações de suplementação alimentar e desempenho de bovinos com 200 e $400 \mathrm{~kg}$ de peso corporal. O Sistema apresenta nas páginas 51 a 55 os procedimentos para formular suplementos para bovinos, sendo necessário o conhecimento da composição e valor nutritivo da pastagem, caso o técnico não deseje utilizar as composições apresentadas.

\section{Resultados e Discussão}

Para formular suplementos alimentares de correção da deficiência nutricional das pastagens, primeiro há necessidade de informações sobre o consumo dos mesmos, que pode variar em função

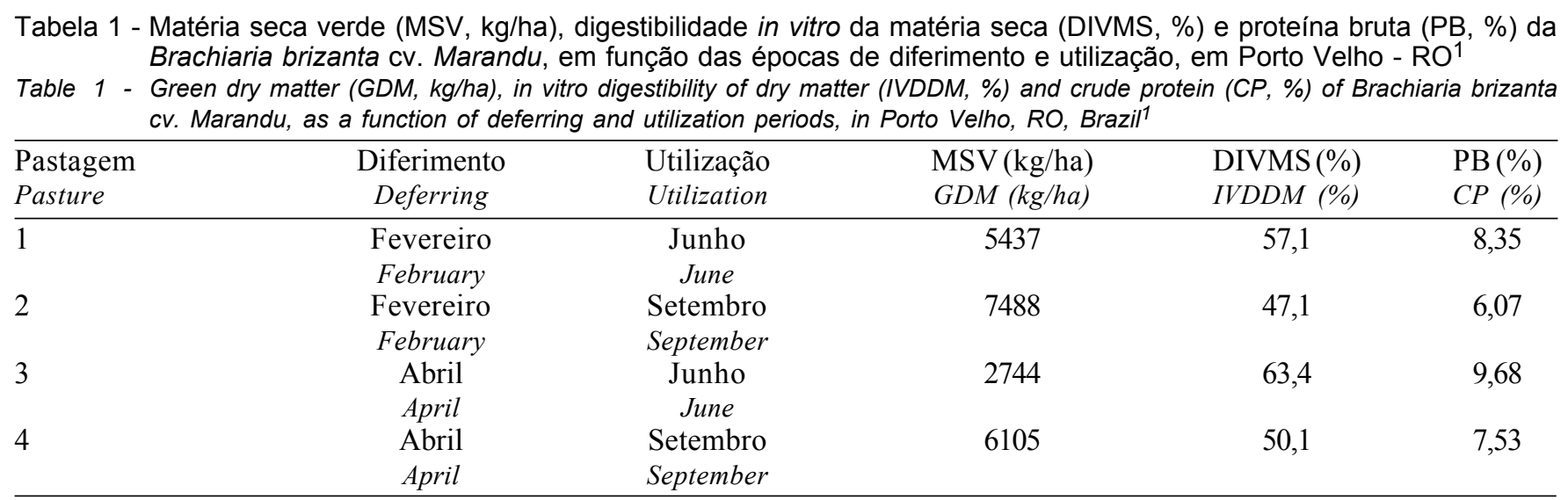

${ }^{1}$ Adaptado de Costa et al. (1993).

Addapted of Costa et al. (1993). 
Tabela 2 - Composição das pastagens utilizadas nas simulações com o Sistema Viçosa de Formulação de Rações (Lana, 2000) Table 2 - Composition of pastures used in the simulations with the computer system of ration formulation (Lana, 2000)

\begin{tabular}{|c|c|c|c|c|c|c|c|c|}
\hline $\begin{array}{l}\text { Pastagem } \\
\text { Pasture }\end{array}$ & $\begin{array}{l}\mathrm{NDT} \\
T D N\end{array}$ & $\begin{array}{l}\mathrm{PB} \\
C P\end{array}$ & $\mathrm{Ca}$ & $\mathrm{P}$ & $\mathrm{Mg}$ & $\mathrm{Na}$ & $\mathrm{K}$ & $\mathrm{S}$ \\
\hline \multicolumn{9}{|c|}{$\begin{array}{c}\% \text { da matéria seca } \\
\% \text { of dry matter }\end{array}$} \\
\hline 1 & 57,1 & 8,35 & 0,30 & 0,18 & 0,22 & 0,01 & 1,90 & 0,10 \\
\hline 2 & 47,1 & 6,07 & 0,41 & 0,12 & 0,34 & 0,01 & 1,16 & 0,10 \\
\hline 3 & 63,4 & 9,68 & 0,30 & 0,18 & 0,22 & 0,01 & 1,90 & 0,10 \\
\hline 4 & 50,1 & 7,53 & 0,41 & 0,12 & 0,34 & 0,01 & 1,16 & 0,10 \\
\hline \multirow{2}{*}{$\begin{array}{l}\text { Pastagem } \\
\text { Pasture }\end{array}$} & & $\mathrm{Cu}$ & $\mathrm{Zn}$ & $\mathrm{Fe}$ & $\mathrm{Mn}$ & I & $\mathrm{Co}$ & $\mathrm{Se}$ \\
\hline & & \multicolumn{7}{|c|}{$\begin{array}{c}\mathrm{mg} / \mathrm{kg} \text { de matéria seca } \\
\mathrm{mg} / \mathrm{kg} \text { of dry matter }\end{array}$} \\
\hline 1 & & 4 & 38 & 150 & 157 & 0,25 & 0,06 & 0,04 \\
\hline 2 & & 4 & 62 & 245 & 211 & 0,25 & 0,06 & 0,04 \\
\hline 3 & & 4 & 38 & 150 & 157 & 0,25 & 0,06 & 0,04 \\
\hline 4 & & 4 & 62 & 245 & 211 & 0,25 & 0,06 & 0,04 \\
\hline
\end{tabular}

do peso corporal e níveis de uréia, sal comum, lipídios, cama-de-frango, entre outros, em sua constituição.

Para que a suplementação proporcione resultados satisfatórios, a pastagem deve apresentar 2,5 toneladas de matéria seca/hectare no início do período seco, devendo no caso da Brachiaria decumbens, apresentar 20-30 cm de altura (Euclides et al., 1998).

Lana (2000) publicou uma equação de estimativa de ganho de peso, em função do consumo de suplemento múltiplo, e outra relacionada com o consumo de suplemento, em função do teor de uréia, sal mineral e peso corporal para bovinos em crescimento em regime de pastagens, baseando-se em dados publicados por Paulino $(1998,1999)$.

Constam da Tabela 3 as estimativas do consumo de suplemento múltiplo para bovinos com diferentes pesos corporais, desenvolvida a partir da equação de estimativa de consumo de suplemento múltiplo. $\mathrm{O}$ teor de mistura mineral no suplemento foi ajustado para assegurar a ingestão de $50 \mathrm{~g}$ de mistura mineral/ animal/dia. Os resultados demonstram que a uréia reduziu com maior intensidade o consumo do suplemento em bovinos mais leves.

Uma vez que a uréia é tóxica, mesmo aos ruminantes, sem prévia adaptação, deve-se inicialmente fornecê-la com a mistura mineral na proporção de 1:1. Após os animais se acostumarem com a uréia (uma semana), adicionar os outros ingredientes em níveis crescentes até alcançar o nível desejado (mais duas semanas). Outra maneira seria misturar a uréia e os outros ingredientes (mistura 1) e a mistura mineral (mistura 2), fornecendo inicialmente as duas misturas na proporção de $1: 1$, reduzindo-se o teor da mistura 2 com conseqüente aumento da mistura 1 , até atingir a fórmula final, dentro de um prazo de duas semanas.

Freitas et al. (2000) conduziram um experimento para avaliar os efeitos dos níveis de uréia e cama-defrangos sobre o consumo de suplementos por novilhos de diferentes pesos corporais $(200,300$ e $400 \mathrm{~kg})$, em regime de confinamento. Constam na Tabela 4 os dados estimados por modelo de regressão, que apresentou alto coeficiente de determinação $\left(\mathrm{R}^{2}=82 \%\right)$.

A uréia foi mais eficiente em reduzir o consumo de suplemento em bovinos mais leves. No caso dos animais pesados, a cama-de-frango feita com sabugo de milho triturado, embora tenha sido de boa qualidade, restringiu eficientemente o consumo do suplemento, evitando consumo excessivo de uréia (Tabela 4). Outra vantagem da cama-de-frango é que, devido aos seus altos teores de $\mathrm{Ca}, \mathrm{P}$ e $\mathrm{Na}$, contribui para reduzir a necessidade de suplementação desses minerais. Por exemplo, $500 \mathrm{~g}$ de cama-de-frango ( $1 \%$ de $\mathrm{P})$ fornecem a mesma quantidade de fósforo que 60 gramas de uma mistura mineral comercial com $8 \%$ de $\mathrm{P}$.

Visando comparar o consumo de suplementos por bovinos em pastejo (CsuplPAS) e em confinamento (CsuplCON), em função do peso corporal (PC, $\mathrm{kg}$ ) e nível de uréia no suplemento, foram obtidas as seguintes equações de regressão: 
Tabela 3 - Consumo de suplemento alimentar (CSupl) e de mistura mineral (CMM) por bovinos em pastagens, em função do peso corporal (PV) e dos níveis de uréia e de mistura mineral (MM) no suplemento

Table 3 - Intake of feed supplement (Csupl) and mineral mixture (CMM) by bovines in pasture as a function of body weight (BW), and levels of urea and mineral mixture (MM) in the supplement

\begin{tabular}{|c|c|c|c|c|}
\hline $\begin{array}{c}\mathrm{PV}(\mathrm{kg}) \\
B W\end{array}$ & $\begin{array}{l}\text { \%Uréia } \\
\text { \%Urea }\end{array}$ & $\begin{array}{l}\% \mathrm{MM} \\
\% M M\end{array}$ & $\begin{array}{c}\text { CSupl g/animal/dia } \\
\text { g/animal/day }\end{array}$ & $\begin{array}{c}\mathrm{CMM} \text { g/animal/dia } \\
\text { g/animal/day }\end{array}$ \\
\hline 150 & 0,0 & 3,4 & 1500 & 50 \\
\hline 150 & 2,9 & 5,0 & 1000 & 50 \\
\hline 150 & 5,4 & 10,0 & 500 & 50 \\
\hline 150 & 5,5 & 20,0 & 250 & 50 \\
\hline 200 & 1,3 & 2,5 & 2000 & 50 \\
\hline 200 & 4,4 & 3,4 & 1500 & 50 \\
\hline 200 & 7,4 & 5,0 & 1000 & 50 \\
\hline 200 & 9,8 & 10,0 & 500 & 50 \\
\hline 200 & 10,0 & 20,0 & 250 & 50 \\
\hline 250 & 2,7 & 2,0 & 2500 & 50 \\
\hline 250 & 5,8 & 2,5 & 2000 & 50 \\
\hline 250 & 8,9 & 3,4 & 1500 & 50 \\
\hline 250 & 11,9 & 5,0 & 1000 & 50 \\
\hline 250 & 14,3 & 10,0 & 500 & 50 \\
\hline 250 & 14,5 & 20,0 & 250 & 50 \\
\hline 300 & 4,0 & 1,6 & 3000 & 50 \\
\hline 300 & 7,2 & 2,0 & 2500 & 50 \\
\hline 300 & 10,3 & 2,5 & 2000 & 50 \\
\hline 300 & 13,4 & 3,4 & 1500 & 50 \\
\hline 300 & 16,3 & 5,0 & 1000 & 50 \\
\hline 300 & 18,8 & 10,0 & 500 & 50 \\
\hline 300 & 18,9 & 20,0 & 250 & 50 \\
\hline 350 & 2,2 & 1,2 & 4000 & 50 \\
\hline 350 & 8,5 & 1,6 & 3000 & 50 \\
\hline 350 & 14,8 & 2,5 & 2000 & 50 \\
\hline 350 & 20,8 & 5,0 & 1000 & 50 \\
\hline 350 & 23,3 & 10,0 & 500 & 50 \\
\hline 350 & 23,4 & 20,0 & 250 & 50 \\
\hline 400 & 6,6 & 1,2 & 4000 & 50 \\
\hline 400 & 13,0 & 1,6 & 3000 & 50 \\
\hline 400 & 19,0 & 2,5 & 2000 & 50 \\
\hline 400 & 25,3 & 5,0 & 1000 & 50 \\
\hline 400 & 27,8 & 10,0 & 500 & 50 \\
\hline 400 & 27,9 & 20,0 & 250 & 50 \\
\hline
\end{tabular}

CsuplPAS $(\mathrm{g} / \mathrm{animal} / \mathrm{dia})=-637+(14,2 * \mathrm{PC})-$ (157*\%uréia) $\mathrm{r}^{2}=52 \%$

CsuplCON $(\mathrm{g} /$ animal $/$ dia $)=183+(12,0 * \mathrm{PC})-$ (160*\%uréia) $\quad r^{2}=85 \%$

A primeira equação foi desenvolvida com base no banco de dados que gerou a Tabela 3 e a segunda equação com base no banco de dados que gerou a Tabela 4, utilizando somente os tratamentos que não incluíam a cama-de-frangos.

Os parâmetros das equações confirmam as similaridades dos efeitos do peso corporal e níveis de uréia sobre o consumo de suplemento alimentar por bovinos em crescimento, tanto em pastagens quanto em confinamento.
Ao se correlacionarem os dados estimados pelas equações acima, para pesos corporais e níveis de uréia semelhantes, verificam-se elevados valores de correlações entre o peso corporal $(r>0,70)$ e o nível de uréia $(\mathrm{r}<-0,60)$ sobre o consumo de suplemento, tanto nos animais sob pastejo quanto em confinamento (Tabela 5). Verifica-se, ainda, que o consumo de suplementos por bovinos sob pastejo e em confinamento, em função do peso corporal e nível de uréia, foi altamente correlacionado $(r=0,95)$. Portanto, nas condições destes experimentos, pode-se afirmar que o monitoramento do consumo de suplemento alimentar por animais em confinamento pode ser extrapolado para as condições de pastagens, no período da seca. 
Tabela 4 - Consumo de suplemento alimentar (Csupl) por bovinos confinados, em função do peso corporal (PV) e níveis de uréia (\% UR) e cama-de-frango (\% CFr) no suplemento, com cana-de-açúcar como volumoso

Table 4 - Intake of feed supplement (Csupl, $\mathrm{kg} /$ day) by confined bovines, as a function of body weight (BW), and levels of urea (\% Ur) and poultry litter (\% CFr) in the supplement, and sugarcane as forage

\begin{tabular}{lcccc}
\hline PV $(\mathrm{kg})$ & $\%$ Ur & $\%$ CFr & $\%$ FTr $^{1}$ & CSupl (kg/dia) \\
$B W$ & & & & \\
\hline 200 & 0 & 0 & 100 & 1,9 \\
200 & 0 & 50 & 50 & 3,3 \\
200 & 5 & 0 & 95 & 1,5 \\
200 & 5 & 50 & 45 & 2,3 \\
200 & 10 & 0 & 90 & 1,2 \\
200 & 10 & 50 & 40 & 1,3 \\
200 & 15 & 0 & 85 & 0,9 \\
200 & 15 & 50 & 35 & 0,3 \\
300 & 0 & 0 & 100 & 3,8 \\
300 & 0 & 50 & 50 & 3,4 \\
300 & 5 & 0 & 95 & 3,0 \\
300 & 5 & 50 & 45 & 2,4 \\
300 & 10 & 0 & 90 & 2,2 \\
300 & 10 & 50 & 40 & 1,5 \\
300 & 15 & 0 & 85 & 1,4 \\
300 & 15 & 50 & 35 & 0,5 \\
400 & 0 & 0 & 100 & 5,7 \\
400 & 0 & 50 & 50 & 3,4 \\
400 & 5 & 0 & 95 & 4,4 \\
400 & 5 & 50 & 45 & 2,5 \\
400 & 10 & 0 & 90 & 3,1 \\
400 & 10 & 50 & 40 & 1,7 \\
400 & 15 & 0 & 85 & 1,9 \\
400 & 15 & 50 & 35 & 0,8 \\
\hline $1 F a$ & & 50 &
\end{tabular}

${ }^{1}$ Farelo de trigo, para completar $100 \%$ do suplemento. Wheat middlings, in order to complete $100 \%$ of the supplement.
$500 \mathrm{~g}$ de suplemento/animal/dia é suficiente para se elevar o nível de PB da dieta consumida ao requerimento necessário para o ganho de peso, em função do nível de energia da pastagem.

Para suprir as exigências de proteína do animal de $200 \mathrm{~kg}$ na pastagem 1, é possível verificar na Tabela 3 que há necessidade do uso de $9,8 \%$ de uréia para restringir o consumo de suplemento em $0,5 \mathrm{~kg} / \mathrm{animal} /$ dia. Assim, utilizaram-se estas recomendações, como pode ser visto nas Tabelas 6 e 7 . Entretanto, foi necessário adicionar $63,1 \%$ de farelo de soja no suplemento (Tabela 7), pois o nível de energia da pastagem permitiu o ganho de $0,76 \mathrm{~kg} / \mathrm{animal} / \mathrm{dia}$ e a dieta deveria, portanto, apresentar $12,4 \%$ de PB (Tabela 6). Neste suplemento, a uréia forneceu $0,127 \mathrm{~kg} / \mathrm{dia}$ de $\mathrm{PB}(0,5 *(9,7 / 100) * 2,62)$, enquanto o farelo de soja forneceu $0,142 \mathrm{~kg}$ de PB $\left(0,5^{*}(63,1 /\right.$ $\left.100)^{*}(45 / 100)\right)$, em que 0,5 é o consumo de suplemento, 9,7 é o teor de uréia no suplemento, 2,62 é o fator de conversão de $\mathrm{g}$ de uréia em $\mathrm{g}$ de proteína bruta pela ação microbiana ruminal, 63,1 é o teor de farelo de soja no suplemento e 45 é o teor de proteína bruta do farelo de soja na matéria natural.

Apesar de o consumo de mistura mineral no suplemento de correção não ter sido alterado em relação ao consumo do suplemento mineral exclusivo (50 g/animal/dia em ambos os casos, Tabela 6), a fórmula da mistura mineral mudou (Tabela 7), pois houve possibilidade de redução de fosfato bicálcico, devido ao maior conteúdo de fósforo presente no farelo de soja.

Animais com $200 \mathrm{~kg}$ de peso corporal na pastagem 1, que apresenta $57,1 \%$ de NDT (Tabela 1), têm potencial de ganho de $0,72 \mathrm{~kg} /$ dia em função do nível de energia (Tabela 6). Para atender às necessidades de minerais para este nível de ganho, formulou-se uma mistura mineral, em que os animais necessitaram consumir $50 \mathrm{~g} /$ dia da mesma. Neste caso, a resposta dos animais ao suplemento mineral pode tornar-se limitada, uma vez que a proteína é o nutriente limitante, não permitindo o atendimento das exigências nutricionais de mantença (Tabela 6).

Portanto, há necessidade de fazer a suplementação de correção, em que além dos minerais, deve-se fornecer um suplemento que supra as necessidades de proteína para que os animais atinjam o ganho de peso esperado em função do nível de energia da pastagem. Muitas vezes, um consumo de
Tabela 5 - Coeficientes de correlações lineares entre o peso corporal (PV), nível de uréia no suplemento (\%Uréia) e o consumo de suplemento alimentar por bovinos em crescimento em regime de pastagem (CsupIPAS) e em confinamento (CsuplCON)

Table 5 - Coefficients of linear correlation among body weight $(B W)$, level of urea in the supplement (\%Urea) and intake of feed supplement by growing bovines in pasture (CsupIPAS) and in confinement (Csup/CON)

\begin{tabular}{lccc}
\hline & $\begin{array}{c}\text { PV }(\mathrm{kg}) \\
B W\end{array}$ & $\begin{array}{c}\text { \%Uréia } \\
\text { \%Urea }\end{array}$ & $\begin{array}{c}\text { CSuplPAS } \\
\text { g/animal/dia- } \\
\text { g/animal/day }\end{array}$ \\
\hline \%Uréia & 0,00 & & \\
CsuplPAS & 0,80 & $-0,60$ & 0,95 \\
CsuplCON & 0,70 & $-0,64$ & 0 \\
\hline
\end{tabular}


Para ganhos de $1 \mathrm{~kg} /$ dia, além do suprimento de proteína e minerais, há necessidade do suprimento de fontes de concentrados energéticos. No caso da pastagem 1 e para animais com $200 \mathrm{~kg}$ de peso corporal, houve necessidade do fornecimento de $2,16 \mathrm{~kg}$ de suplemento (Tabela 6). Ao consultar a Tabela 3, observa-se que, para animais com $200 \mathrm{~kg}$ consumirem 2,0 kg de suplemento, há necessidade de 1,3\% de uréia no mesmo.

Ao se formularem suplementos, é importante fazer o cálculo da relação benefício/custo, pois o custo com suplementação/animal/dia, em função dos

Tabela 6 - Consumos de matéria seca (CMS), de suplemento alimentar (Csupl) e de mistura mineral (CMM), em kg/animal/ dia, custo com suplementação (\$, em R \$/animal/dia), suprimento de nutrientes (\% da matéria seca da dieta) e ganho de peso esperado, em função do nível de energia e proteína da dieta, em bovinos com $200 \mathrm{~kg}$ de peso corporal, em pastagens

Table 6 - Intakes of dry matter (CMS), feed supplement (Csupl) and mineral mixture (CMM), in kg/animal/day, supplementation cost (\$, in Real/animal/day), nutrients supply (\% of feed dry matter) and expected daily gain (GDP), as a function of energy and protein levels in the diet, in bovines with $200 \mathrm{~kg}$ of body weight, in pastures

\begin{tabular}{|c|c|c|c|c|c|c|c|c|c|c|}
\hline \multirow[t]{3}{*}{ Past. } & \multirow{3}{*}{$\begin{array}{l}\text { Suplemento } \\
\text { Supplement } 1\end{array}$} & CMS & Csupl & CMM & \multirow[t]{3}{*}{$\$$} & \multicolumn{3}{|c|}{ Nutrientes (\%MS) } & \multicolumn{2}{|c|}{$\operatorname{GDP}(\mathrm{kg} / \mathrm{d})$} \\
\hline & & \multirow{2}{*}{\multicolumn{3}{|c|}{$\begin{array}{l}\mathrm{kg} / \text { animal/dia } \\
\mathrm{kg} / \text { animal/day }\end{array}$}} & & NDT & PB & PDR & $\mathrm{f}(\mathrm{NDT})$ & $\mathrm{f}(\mathrm{PB})$ \\
\hline & & & & & & $T D N$ & $C P$ & $R D P$ & $f(T D N)$ & $f(C P)$ \\
\hline 1 & Mist. Mineral & 6,2 & 0,05 & 0,05 & 0,02 & 56,6 & 8,3 & 5,0 & 0,72 & 0,00 \\
\hline 1 & Supl. Correção & 6,2 & 0,50 & 0,05 & 0,22 & 57,6 & 12,4 & 8,3 & 0,76 & 0,76 \\
\hline 1 & Supl. $(1 \mathrm{~kg} / \mathrm{d})$ & 6,1 & 2,16 & 0,06 & 0,75 & 63,5 & 13,6 & 8,3 & 1,00 & 1,00 \\
\hline 2 & Mist. Mineral & 6,4 & 0,04 & 0,04 & 0,03 & 46,8 & 6,0 & 3,0 & 0,32 & 0,00 \\
\hline 2 & Supl. Correção & 6,4 & 0,50 & 0,03 & 0,23 & 48,6 & 10,4 & 6,5 & 0,40 & 0,40 \\
\hline 2 & Supl. $(1 \mathrm{~kg} / \mathrm{d})$ & 6,1 & 3,60 & 0,06 & 1,19 & 63,5 & 13,6 & 7,7 & 1,00 & 1,00 \\
\hline 3 & Mist. Mineral & 6,1 & 0,06 & 0,06 & 0,03 & 62,8 & 9,6 & 5,8 & 0,97 & 0,23 \\
\hline 3 & Supl. Correção & 6,1 & 0,50 & 0,06 & 0,22 & 63,4 & 13,6 & 9,0 & 0,99 & 0,99 \\
\hline 3 & Supl. $(1 \mathrm{~kg} / \mathrm{d})$ & 6,1 & 0,50 & 0,06 & 0,22 & 63,4 & 13,6 & 9,0 & 1,00 & 1,00 \\
\hline 4 & Mist. Mineral & 6,4 & 0,04 & 0,04 & 0,03 & 49,8 & 7,5 & 3,8 & 0,44 & 0,00 \\
\hline 4 & Supl. Correção & 6,3 & 0,50 & 0,04 & 0,21 & 51,3 & 11,0 & 6,7 & 0,50 & 0,50 \\
\hline 4 & Supl. (1 kg/d) & 6,1 & 3,23 & 0,06 & 1,08 & 63,5 & 13,6 & 7,7 & 1,00 & 1,00 \\
\hline
\end{tabular}

${ }^{1}$ Mineral mixture, correction supplement and supplement for gain of $1 \mathrm{~kg} / \mathrm{animal} / \mathrm{day}$.

Tabela 7 - Fórmulas dos suplementos múltiplo e mineral para bovinos com $200 \mathrm{~kg}$ de peso corporal, em função do ganho e composição da pastagem

Table 7 - Composition of the feed and mineral supplements for bovines with $200 \mathrm{~kg}$ of body weight, as a function of weight gain and pasture composition

\begin{tabular}{|c|c|c|c|c|c|c|c|c|c|c|c|c|}
\hline \multirow[t]{2}{*}{ Past. } & \multirow[t]{2}{*}{$\begin{array}{l}\text { Suplemento }^{3} \\
\text { Supplement }\end{array}$} & \multicolumn{4}{|c|}{$\begin{array}{l}\% \text { do suplemento }{ }^{1} \\
\% \text { of supplement }\end{array}$} & \multicolumn{7}{|c|}{$\begin{array}{l}\% \text { da mistura mineral }(\mathrm{MM})^{2} \\
\% \text { of mineral mixture }(M M)^{2}\end{array}$} \\
\hline & & $\mathrm{Mi}$ & FS & Ur & $\mathrm{MM}$ & $\mathrm{CC}$ & FB & SM & $\mathrm{CS}$ & $\mathrm{BK}$ & $\mathrm{FE}$ & $\mathrm{Mc}$ \\
\hline 1 & Mist. Mineral & 0,0 & 0,0 & 0,0 & 100 & 40 & 23 & 0,0 & 29 & 0,0 & 6,4 & 1,0 \\
\hline 1 & Supl. Correção & 17,3 & 63,1 & 9,7 & 9,9 & 49 & 16 & 0,0 & 29 & 0,0 & 4,7 & 1,0 \\
\hline 1 & Supl. $(1 \mathrm{~kg} / \mathrm{d})$ & 68,8 & 27,0 & 1,4 & 2,8 & 75 & 0 & 0,0 & 22 & 0,0 & 1,9 & 1,0 \\
\hline 2 & Mist. Mineral & 0,0 & 0,0 & 0,0 & 100 & 0 & 51 & 0,0 & 39 & 0,0 & 9,0 & 0,4 \\
\hline 2 & Supl. Correção & 11,6 & 72,7 & 9,7 & 6,0 & 0 & 44 & 0,0 & 47 & 0,0 & 7,7 & 0,5 \\
\hline 2 & Supl. $(1 \mathrm{~kg} / \mathrm{d})$ & 77,3 & 20,2 & 0,9 & 1,7 & 77 & 0 & 0,0 & 21 & 0,0 & 0,9 & 0,8 \\
\hline 3 & Mist. Mineral & 0,0 & 0,0 & 0,0 & 100 & 36 & 35 & 0,0 & 23 & 0,0 & 5,0 & 0,8 \\
\hline 3 & Supl. Correção & 15,3 & 62,8 & 9,8 & 12,1 & 47 & 25 & 0,0 & 23 & 0,0 & 3,8 & 0,8 \\
\hline 3 & Supl. (1 kg/d) & 15,3 & 62,8 & 9,8 & 12,1 & 47 & 25 & 0,0 & 23 & 0,0 & 3,8 & 0,8 \\
\hline 4 & Mist. Mineral & 0,0 & 0,0 & 0,0 & 100 & 0 & 60 & 0,0 & 33 & 0,0 & 7,5 & 0,3 \\
\hline 4 & Supl. Correção & 36,4 & 46,6 & 9,7 & 7,3 & 0 & 53 & 0,0 & 39 & 0,0 & 7,4 & 0,3 \\
\hline 4 & Supl. $(1 \mathrm{~kg} / \mathrm{d})$ & 77,8 & 19,5 & 0,9 & 1,8 & 72 & 4 & 0,0 & 22 & 0,0 & 1,4 & 0,7 \\
\hline
\end{tabular}

${ }^{1} \mathrm{Mi}=$ milho; $\mathrm{FS}=$ farelo de soja; $\mathrm{Ur}=$ uréia; $\mathrm{MM}=$ mistura mineral.

${ }^{2} \mathrm{CC}$ = calcário; FB = fosfato bicálcico; $\mathrm{SM}$ = sulfato de magnésio; CS = cloreto de sódio; BK = bicarbonato de potássio; FE = flor de enxofre; Mc = suplemento de microminerais.

${ }^{1} \mathrm{Mi}=$ corn; $F S=$ soybean meal; $U r=$ urea; $M M=$ mineral misture.

${ }^{2} C C=$ limestone; $F B=$ dicalcium phosphate; $S M=$ magnesium sulphate; $C S=$ sodium chloride; $B K=$ potassium bicarbonate; $F E=$ sulphur; $M C=$ microminerals supplement.

${ }^{3}$ Mineral mixture, correction supplement and supplement for gain of $1 \mathrm{~kg} / \mathrm{animal} / \mathrm{day}$. 
preços adotados $(\mathrm{R} \$ / \mathrm{kg}=0,47,0,32,0,52$ e 0,70 para o farelo de soja, milho, uréia e mistura mineral, respectivamente), elevou de $\mathrm{R} \$ 0,22$ para $\mathrm{R} \$ 0,75$, enquanto o ganho elevou de 0,76 para $1 \mathrm{~kg} / \mathrm{dia}$. Convertendo o ganho para preço de carcaça comercializável, obteve-se R $\$ 0,35((1-0,76) * 0,54 * 1 /$ $15 * 41)$, em que 0,54 é o rendimento de carcaça; $1 / 15$ é para converter $\mathrm{kg}$ em arroba; e 41 é o custo por arroba de carcaça comercializável. Neste caso, o custo com suplementação aumentou R \$ 0,53/animal/ dia e o retorno foi de 0,35 ; não sendo, portanto, econômica a suplementação. Entretanto, ao se fazer a suplementação, outros fatores devem ser levados em consideração, como a redução da idade ao primeiro parto, diminuição da idade ao abate e redução no intervalo de partos. Também, dependendo do preço de comercialização da carne bovina e dos ingredientes alimentares, em certas épocas a suplementação pode ser viável.

Ao comparar as diferentes condições das pastagens, verifica-se que, para um animal de $200 \mathrm{~kg}$ de peso corporal ganhar $1 \mathrm{~kg} / \mathrm{dia}$, houve necessidade de 2,16; 3,60; 0,50; e 3,23 kg de suplemento/animal/dia (Tabela 6). Quando o peso corporal dos animais era de $400 \mathrm{~kg}$, a necessidade de suplementação era ainda maior, ou seja, 4,21; 5,86;2,48; e 5,24 kg/animal/dia (Tabela 8). Portanto, quanto maior a necessidade de suplementação, como no caso de animais mais pesados, o melhor seria utilizar pastagens de mais alta qualida- de ou conduzi-los ao confinamento de terminação, com uso de volumosos de melhor qualidade, objetivando reduzir o custo com suplementação.

Uma das grandes vantagens do confinamento é o aproveitamento do ganho compensatório apresentado pelos animais. Isto porque, devido ao menor tamanho dos órgãos internos no período de restrições nas pastagens, ao entrarem no confinamento, os requerimentos nutricionais de mantença desses animais serão baixos, com menor necessidade de alimentação para suprir as exigências de mantença. Com isto, sobram mais nutrientes, permitindo ganhos de peso mais elevados.

Com o avanço do confinamento, os órgãos internos começam a aumentar, elevando-se as exigências de energia para mantença, e os animais passam a aumentar a deposição de gordura, elevando-se as exigências nutricionais de energia para ganho de peso. Portanto, a eficiência alimentar cai linearmente com o avançar do confinamento, onerando o custo de produção. Para reduzir os custos, o ideal é fazer confinamentos de terminação de 2 a 3 meses apenas.

Pelos dados expostos na Tabela 6, observa-se que animais em crescimento $(200 \mathrm{~kg}$ de peso corporal) estão sujeitos à deficiência de proteína, devido à maior exigência da mesma, sendo oportuno o uso da suplementação de correção. Além disso, a uréia funciona muito bem na restrição do consumo de

Tabela 8 - Consumos de matéria seca (CMS), suplemento alimentar (Csupl) e de mistura mineral, em $\mathrm{kg} / \mathrm{animal} / \mathrm{dia}$, custo com suplementação (\$, em R \$/animal/dia), suprimento de nutrientes (\% da matéria seca da dieta) e ganho de peso esperado em função do nível de energia e proteína da dieta, em bovinos com $400 \mathrm{~kg}$ de peso corporal, em pastagens

Table 8 - Intakes of dry matter (CMS), feed supplement (Csupl) and mineral mixture (CMM), in kg/animal/day, supplementation cost (\$, in Real/animal/day), nutrients supply (\% of feed dry matter) and expected daily gain (GDP) as a function of energy and protein levels in the diet, in bovines with $400 \mathrm{~kg}$ of body weight, in pastures

\begin{tabular}{|c|c|c|c|c|c|c|c|c|c|c|}
\hline \multirow[t]{3}{*}{ Past. } & \multirow{3}{*}{$\begin{array}{l}\text { Suplemento } \\
\text { Supplement }^{1}\end{array}$} & CMS & Csupl & CMM & \multirow[t]{3}{*}{$\$$} & \multicolumn{3}{|c|}{ Nutrientes (\%MS) } & \multicolumn{2}{|c|}{$\operatorname{GDP}(\mathrm{kg} / \mathrm{d})$} \\
\hline & & \multirow{2}{*}{\multicolumn{3}{|c|}{$\begin{array}{l}\mathrm{kg} / \mathrm{animal} / \mathrm{dia} \\
\mathrm{kg} / \text { animal/day }\end{array}$}} & & NDT & PB & PDR & $\mathrm{f}(\mathrm{NDT})$ & $\mathrm{f}(\mathrm{PB})$ \\
\hline & & & & & & $T D N$ & $C P$ & $R D P$ & $f(T D N)$ & $f(C P)$ \\
\hline 1 & Mist. Mineral & 10 & 0,03 & 0,03 & 0,02 & 56,9 & 8,3 & 5,0 & 0,73 & 0,85 \\
\hline 1 & Supl. Correção & 10 & 0,03 & 0,03 & 0,02 & 56,9 & 8,3 & 5,0 & 0,73 & 0,85 \\
\hline 1 & Supl. (1 kg/d) & 10 & 4,21 & 0,06 & 1,32 & 63,5 & 14,9 & 5,0 & 1,00 & 2,10 \\
\hline 2 & Mist. Mineral & 10 & 0,03 & 0,03 & 0,02 & 47,0 & 6,1 & 3,0 & 0,33 & 0,00 \\
\hline 2 & Supl. Correção & 10 & 0,24 & 0,03 & 0,10 & 47,1 & 8,0 & 4,9 & 0,33 & 0,79 \\
\hline 2 & Supl. $(1 \mathrm{~kg} / \mathrm{d})$ & 10 & 5,86 & 0,06 & 1,77 & 63,4 & 9,3 & 4,8 & 1,00 & 1,04 \\
\hline 3 & Mist. Mineral & 10 & 0,03 & 0,03 & 0,02 & 63,2 & 9,7 & 5,8 & 0,98 & 1,12 \\
\hline 3 & Supl. Correção & 10 & 0,03 & 0,03 & 0,02 & 63,2 & 9,7 & 5,8 & 0,98 & 1,12 \\
\hline 3 & Supl. (1 kg/d) & 10 & 2,48 & 0,04 & 0,85 & 63,5 & 20,8 & 7,1 & 1,00 & 3,20 \\
\hline 4 & Mist. Mineral & 10 & 0,03 & 0,03 & 0,02 & 49,9 & 7,5 & 3,8 & 0,45 & 0,70 \\
\hline 4 & Supl. Correção & 10 & 0,03 & 0,03 & 0,02 & 49,9 & 7,5 & 3,8 & 0,45 & 0,70 \\
\hline 4 & Supl. $(1 \mathrm{~kg} / \mathrm{d})$ & 10 & 5,24 & 0,05 & 1,58 & 63,5 & 9,0 & 4,3 & 1,00 & 1,00 \\
\hline
\end{tabular}

${ }^{1}$ Mineral mixture, correction supplement and supplement for gain of $1 \mathrm{~kg} / \mathrm{animal} / \mathrm{day}$. 
suplemento. Já a suplementação energética para ganhos de peso mais elevados pode ser viável ou não.

Em animais de pesos corporais mais elevados (400 kg), não houve necessidade de suplementação de correção (suplementação nitrogenada), exceto na pastagem 2, pois aquelas pastagens continham suficiente quantidade de proteína, devido à menor exigência da mesma com o avanço da idade dos animais (Tabela 8). Além do mais, a uréia não é bom inibidor de consumo em animais pesados, uma vez que, para se restringir o consumo de suplemento para $2,48 \mathrm{~kg} /$ animal/dia na pastagem 3 (Tabela 8 ), houve necessidade de $16,5 \%$ de uréia (Tabela 9), conforme recomendação apresentada na Tabela 3, elevando-se o teor de proteína bruta da dieta consumida (pastagem + suplemento) para $20,8 \%$ (Tabela 8).

Uma vez que a suplementação energética fica mais onerosa em animais mais pesados em pastagens, e não havendo necessidade da suplementação protéica, a suplementação mineral exclusiva pode ser a alternativa apropriada em muitas situações. Além do mais, observa-se pela fórmula da mistura mineral indicada para os animais com $400 \mathrm{~kg}$ de peso corporal (Tabela 9), que praticamente não houve necessidade de suplementação de fósforo, e houve menor necessidade de suplementação de cálcio, devido às pastagens apresentarem quantidades suficientes para suprir os requerimentos nutricionais, que reduzem com o avanço da idade dos animais.

Tabela 9 - Fórmulas dos suplementos múltiplo e mineral para bovinos com $400 \mathrm{~kg}$ de peso corporal, em função do ganho e da composição da pastagem

Table 9 - Composition of the feed and mineral supplements for bovines with $400 \mathrm{~kg}$ of body weight, as a function of weight gain and pasture composition

\begin{tabular}{|c|c|c|c|c|c|c|c|c|c|c|c|c|}
\hline \multirow[t]{2}{*}{ Past. } & \multirow[t]{2}{*}{$\begin{array}{l}\text { Suplemento }^{3} \\
\text { Supplement }\end{array}$} & \multicolumn{4}{|c|}{$\begin{array}{l}\% \text { do suplemento } \\
\\
\% \text { of supplement }\end{array}$} & \multicolumn{7}{|c|}{$\begin{array}{c}\% \text { da mistura mineral }(\mathrm{MM})^{2} \\
\% \text { of mineral mixture }(M M)^{2}\end{array}$} \\
\hline & & $\mathrm{Mi}$ & $\mathrm{FS}$ & $\mathrm{Ur}$ & $\mathrm{MM}$ & $\mathrm{CC}$ & FB & SM & $\mathrm{CS}$ & $\mathrm{BK}$ & $\mathrm{FE}$ & $\mathrm{Mc}$ \\
\hline 1 & Mist. Mineral & 0,0 & 0,0 & 0,0 & 100 & 0 & 0,0 & 0,0 & 80 & 0,0 & 17,3 & 2,7 \\
\hline 1 & Supl. Correção & 0,0 & 0,0 & 0,0 & 100 & 0 & 0,0 & 0,0 & 80 & 0,0 & 17,3 & 2,7 \\
\hline 1 & Supl. (1 kg/d) & 93,2 & 0,0 & 5,3 & 1,4 & 47 & 0,0 & 0,0 & 43 & 0,0 & 8,4 & 2,2 \\
\hline 2 & Mist. Mineral & 0,0 & 0,0 & 0,0 & 100 & 0 & 0,7 & 0,0 & 80 & 0,0 & 18,2 & 0,9 \\
\hline 2 & Supl. Correção & 59,5 & 0,0 & 28,6 & 11,9 & 0 & 0,0 & 0,0 & 81 & 0,0 & 18,4 & 0,9 \\
\hline 2 & Supl. (1 kg/d) & 98,2 & 0,0 & 0,9 & 1,0 & 50 & 0,0 & 0,0 & 40 & 0,0 & 7,5 & 1,7 \\
\hline 3 & Mist. Mineral & 0,0 & 0,0 & 0,0 & 100 & 9 & 0,0 & 0,0 & 73 & 0,0 & 15,7 & 2,5 \\
\hline 3 & Supl. Correção & 0,0 & 0,0 & 0,0 & 100 & 9 & 0,0 & 0,0 & 73 & 0,0 & 15,7 & 2,5 \\
\hline 3 & Supl. (1 kg/d) & 81,5 & 0,0 & 16,5 & 2,0 & 18 & 0,0 & 0,0 & 66 & 0,0 & 14,2 & 2,3 \\
\hline 4 & Mist. Mineral & 0,0 & 0,0 & 0,0 & 100 & 0 & 0,7 & 0,0 & 80 & 0,0 & 18,2 & 0,9 \\
\hline 4 & Supl. Correção & 0,0 & 0,0 & 0,0 & 100 & 0 & 0,7 & 0,0 & 80 & 0,0 & 18,2 & 0,9 \\
\hline 4 & Supl. (1 kg/d) & 98,7 & 0,0 & 0,4 & 0,9 & 44 & 0,0 & 0,0 & 45 & 0,0 & 8,6 & 1,6 \\
\hline
\end{tabular}

${ }^{1} \mathrm{Mi}=$ milho; $\mathrm{FS}=$ farelo de soja; $\mathrm{Ur}=$ uréia; $\mathrm{MM}=$ mistura mineral.

${ }^{2} \mathrm{CC}$ = calcário; FB = fosfato bicálcico; SM = sulfato de magnésio; CS = cloreto de sódio; BK = bicarbonato de potássio; FE = flor de enxofre; $\mathrm{Mc}=$ suplemento de microminerais.

${ }^{1} \mathrm{Mi}=$ corn; $F S=$ soybean meal; $U \mathrm{r}=$ urea; $M M=$ mineral misture.

${ }^{2} C C=$ limestone; $F B=$ dicalcium phosphate; $S M=$ magnesium sulphate; $C S=$ sodium chloride; $B K=$ potassium bicarbonate; $F E=$ sulphur Mc = microminerals supplement .

${ }^{3}$ Mineral mixture, correction supplement and supplement for gain of $1 \mathrm{~kg} /$ animal/day.

\section{Conclusões}

O Sistema Viçosa de Formulação de Rações (Lana, 2000) permite o balanceamento de dietas para bovinos em pastagens, levando-se em consideração as necessidades nutricionais dos ani- mais e a composição das forragens. O suprimento dos nutrientes deficientes é realizado em suplementos alimentares, que pode ter seu consumo controlado em função do peso corporal dos animais e uso de uréia, cama-de-frango e sal mineral no suplemento. 


\section{Literatura Citada}

CACHAPUZ, J.M.S. Desmame aos 90 dias: efeito da alimentação no desempenho dos terneiros. Porto Alegre: EMATER. 32p. 1991.

COSTA, N.; OLIVEIRA, J.R.C.; PAULINO, V.T. Efeito de diferimento sobre o rendimento de forragem e composição química de Brachiaria brizanta cv. Marandu em Rondônia. Revista da Sociedade Brasileira de Zootecnia, v.22, n.3, p.495-510, 1993.

EUCLIDES, V.P.B.; EUCLIDES FILHO, K.; ARUDA, Z.J. et al. Desempenho de novilhos em pastagens de Brachiaria decumbens submetidos a diferentes regimes alimentares. Revista da Sociedade Brasileira de Zootecnia, v.27, n.2, p.246-252, 1998.

FREITAS, A.W.P.; LANA, R.P.; CAMPOS, J.M.S. et al. Influência de níveis de uréia e cama de frango sobre o consumo de suplemento concentrado por novilhos mantidos em regime de confinamento. In: REUNIÃO ANUAL DA SOCIEDADE BRASILEIRA DE ZOOTECNIA, 37., 2000, Viçosa-MG. Anais... Viçosa, MG: Sociedade Brasileira de Zootecnia, 2000. p.454.

LANA, R.P. Sistema Viçosa de formulação de rações. Viçosa, MG: Universidade Federal de Viçosa, 2000. 60p.

LESCH, S.F.; PIETERSE, P.J.S.; OOSTHUIZEZ, F.J. et. al. Utilization of the energy in mature veld hay by steers: effect of urea supplementation. Proceedings South African Society of Animal Production, v.2, p.45-57, 1963.

MULLER, I.R.; RESTLE, J.; GRASSI, C. et al. Comparação entre terneiros da raça Charolês, Aberdeen Angus e Devon mantidos em campo nativo e suplementados com resíduo da limpeza de grão de soja e do arroz. In: REUNIÃO ANUAL DA SOCIEDADE BRASILEIRA DE ZOOTECNIA, 17., 1980, Fortaleza. Anais... Fortaleza: Sociedade Brasileira de Zootecnia, 1980. p.13.

PASCOAL, L.L.; RESTLE, J. Suplementação a campo. Técnicas avançadas na recria e engorda de bovinos de corte. Santa Maria: Universidade Federal de Santa Maria, 1996. p.22-34.
PASCOAL, L.L.; BRONDANI, I.L.; RESTLE, J. et al. Características quantitativas de carcaça de vacas submetidas a diferentes níveis de suplementação em pastagem cultivada. In: REUNIÃO ANUAL DA SOCIEDADE BRASILEIRA DE ZOOTECNIA, 34., 1997, Juiz de Fora. Anais... Juiz de Fora: Sociedade Brasileira de Zootecnia, 1997. p.364-366.

PAULINO, M.F. Suplementos múltiplos para recria e engorda de bovinos em pastagens. In: CONEZ-98 - CONGRESSO NACIONAL DOS ESTUDANTES DE ZOOTECNIA, 1998, Viçosa, MG. Anais... Viçosa, MG: Universidade Federal de Viçosa, 1998. p.173-188.

PAULINO, M.F. Misturas múltiplas na nutrição de bovinos de corte a pasto. In: SIMPÓSIO GOIANO SOBRE PRODUÇÃO DE BOVINOS DE CORTE, 1999. Goiânia. Anais... Goiânia, Colégio Brasileiro de Nutrição Animal, 1999. p.95-104.

POPPI, D.P.; McLENNAN, S.R. Protein and energy utilization by ruminants at pasture. Journal of Animal Science, v.73, p.278-290, 1995.

RESTLE, J.; BRONDANI, I.L.; PASCOAL, L.L. et. al. Técnicas avançadas na recria e engorda de bovinos de corte. Santa Maria: Universidade Federal de Santa Maria, 1997. p.22-35.

SEIFFERT, N.F. Alimentação do rebanho de corte em época seca. Informe Agropecuário, v.8, n.89, p.20-27, 1982.

TOSI, H. Suplementação mineral em pastagem. In: PEIXOTO, A.M.; MOURA, J.C.; FARIA, V.P. (Eds) SIMPÓSIO SOBRE MANEJO DA PASTAGEM, 13., 1997. Piracicaba. Anais... Piracicaba: Fundação da Escola Superior de Agricultura "Luiz Queiroz", 1997. p.151-184.

Van SOEST, P.J. Nutritional ecology of the ruminant. 2.ed. Ithaca: Cornell University, 1994. 476p.

Recebido em: 26/04/01 Aceito em: 17/09/01 